$\begin{gathered}\text { Dicle Üniversitesi Veteriner Fakültesi Dergisi } \\ \text { https://dergipark.org.tr/tr/pub/duvetfd } \\ \text { Araştırma Makalesi/Research Article } \\ \text { Dicle Üniv Vet Fak Derg 2021;14(2):89-95 } \\ \text { DOI: 10.47027/duvetfd.911848 }\end{gathered} \quad$ e-ISSN:1308-0679
ISSN:1307-9972

\title{
Konya Yeşil Peynirlerinin Biyojen Amin İçerikleri ile Bazı Fizikokimyasal ve Mikrobiyolojik Özelliklerinin Belirlenmesi
}

\author{
Nihat TELLi $1, \mathrm{a}, \bowtie$ \\ ${ }^{1}$ Konya Teknik Üniversitesi, Teknik Bilimler Meslek Yüksekokulu, Gıda Teknolojisi Programı, Konya, TÜRKiYE \\ aORCID: 0000-0002-4121-4588
}

Öz

Araştırmada, Konya ilinde satışa sunulan Yeşil peynirlerin biyojen amin içerikleri ile bazı fizikokimyasal ve mikrobiyolojik özellikleri değerlendirildi. Araştırma materyali olarak piyasadan temin edilen 50 adet Konya Yeşil peyniri örneği kullanıldı. Araştırma kapsamında tespit edilen biyojen aminler olan tiramin (50/50), histamin (50/50), kadaverin (44/50), putresin (39/50), triptamin (32/50) ve feniletilamin $(24 / 50)$ için ortalama değerler sırasıyla; $229.41 \pm 95.63,148.21 \pm 55.52,45.34 \pm 29.52,29.03 \pm 27.24,3.14 \pm 2.70$ ve $2.30 \pm 2.37 \mathrm{mg} / \mathrm{kg}$ olarak bulundu. Örneklerde toplam biyojen amin ortalamaları $457.45 \pm 122.23 \mathrm{mg} / \mathrm{kg}$ olarak tespit edilirken spermidin ve spermin varlığı saptanmadı. Tiramin ve histamin miktarlarının toplam biyojen amin ortalamalarının \%82'sini oluşturduğu gözlemlendi. Fizikokimyasal analizlerde örnekler ortalamalarının kuru madde için \%53.57 \pm 2.69 ; tuz için $\% 5.82 \pm 0.81$, asitlik (L.A cinsinden) için $\% 1.13 \pm 0.18$, pH için $6.21 \pm 0.37$ ve $a_{w}$ için $0.948 \pm 0.01$ olduğu belirlendi. Yapılan renk ölçümleri sonucunda; $L$ değerlerinin 66.43 ile $83.11, a$ parametresinin 4.54 ile -2.59 ve $b$ parametresinin de 11.44 ile 20.62 arasında değiştiği saptandı. TMAB, Lactobacillus, Streptococcus ve Lactococcus için ortalama değerler $7.44 \pm 0.58,6.47 \pm 0.26$ ve $7.09 \pm 0.40 \mathrm{log} \mathrm{KOB} / \mathrm{g}$ düzeylerindeydi. Bu çalışma, çiğ sütten üretilen Konya Yeşil peynirinin biyojen amin konsantrasyonlarının ve satış noktalarında biyojen amin oluşumuna neden olabilecek faktörlerin izlenmesinin önemini ortaya koymaktadır. Özellikle baskın biyojen amin türleri göz önüne alındığında Yeşil peynir üretim hattı, depolama, sevkiyat ve satış yerlerinde hijyenik koşulların oluşturulmasının tüketici sağlığının korunması bakımından önem arz ettiği düşünülmektedir.

Anahtar Kelimeler: Konya Yeşil peyniri, biyojen amin, tiramin, histamin, TMAB

Determination of Biogenic Amine Content with Some Physicochemical and Microbiological Properties of Konya Green Cheeses Abstract

In the study, biogenic amine contents and some physicochemical and microbiological properties of retail Green cheeses in Konya province were evaluated. As the research material, 50 Konya Green cheeses samples obtained from the retail market were used. Average values for tyramine (50/50), histamine (50/50), cadaverine (44/50), putrescine (39/50), tryptamine $(32 / 50)$ and phenylethylamine $(24 / 50)$ were found as $229.41 \pm 95.63,148.21 \pm 55.52,45.34 \pm 29.52,29.03 \pm 27.24,3.14 \pm 2.70$ and $2.30 \pm 2.37 \mathrm{mg} / \mathrm{kg}$, respectively. While the total biogenic amine averages in the samples were determined as $457.45 \pm 122.23 \mathrm{mg} / \mathrm{kg}$, spermidine and spermin was not detected. It was observed that the amount of tyramine and histamine constituted $\sim 82 \%$ of the total biogenic amine averages. In physicochemical analysis, the average of the samples was $53.57 \pm 2.69 \%$ for dry matter; $5.82 \pm 0.81 \%$ for salt, $1.13 \pm 0.18 \%$ for acidity (in L.A), $6.21 \pm 0.37$ for $\mathrm{pH}$ and $0.948 \pm 0.01$ for aw. As a result of the color measurements; $L$ values were found to be between 66.43 and 83.11 , a parameter between 4.54 and -2.59 , and b parameter between 11.44 and 20.62. Mean values for TMAB, Lactobacillus, Streptococcus and Lactococcus were $7.44 \pm 0.58,6.47 \pm 0.26$ and $7.09 \pm 0.40 \mathrm{log} C F U / g$. This study demonstrates the importance of monitoring the biogenic amine concentrations of Konya Green cheese produced from raw milk and the factors that may cause biogenic amine formation at sales points. Considering the dominant biogenic amine types, it is thought that creating hygienic conditions in green cheese production line, storage, shipment and sales places is important in terms of protecting consumer health.

Key Words: Konya Green cheese, biogenic amine, tyramine, histamine, TMAB

\section{Giriş}

Konya ili ve çevresinde üretilen bir peynir çeşidi olan Yeşil peynir geleneksel ürünlere olan talebin artmasına paralel olarak daha fazla üretilir ve tercih edilir hale gelmiştir (1). Kuru tipte tulum peynirleri sınıfında değerlendirilen Yeşil peynir, gözeneksiz, parçalanma eğiliminde ve yarı sert bir yapıdadır. Mavi-yeşil renkli olup az miktarda tuzlu lezzete sahiptir. Aromatik nitelikte ve küf karakteristikleri baskın bir peynir türüdür (2). Üretiminde küfle olgunlaştırma aşaması bulunmakta ve bu aşama peynirin karakteristik yapı ve özelliklerinin şekillenmesinde büyük önem taşımaktadır. Üretiminde sıklıkla kuru madde oranı fazla olan koyun sütü tercih edilmektedir. Bununla birlikte keçi sütü ve/veya inek sütü ile karışımları da kullanılabilmektedir. Olgunlaştırma aşamasında oksidatif ransidite ve mikotoksin oluşumunun engellenmesi amacıyla yağsız veya kısmen yağı alınmış sütlerin 
kullanımı yaygındır. Türkiye'nin Doğu Anadolu bölgesinde starter kültür ilavesi yapılmadan ve ısıl işlem görmemiş sütten üretilen tel peynir, üretimin ilk aşamasını teşkil etmektedir. Tel peynirin Yeşil peynir üretim yerlerine sevkiyatı sonrası soğuk muhafazada yaklaşık 90 gün süreyle bekletilmesi gerekmektedir. Soğuk muhafaza sonrası tel peynirler kesilerek üretime uygun nitelikteki kâğıt materyalle kaplanır. Peynir bu aşamadan sonra partiler halinde $22 \pm 2{ }^{\circ} C^{\prime}$ lik kontrollü koşullarda küfle olgunlaştırmaya tabi tutulur. Mavi-yeşil küflerin peynir yüzeyinde gelişimi ile yaklaşık 30 gün süren bu aşama sonlandırılır ve tüketime sunulur $(3,4)$.

Gıda kalitesi anlayışında güvenlik, beslenme, bulunabilirlik, uygunluk, bütünlük ve tazelik ile ilgili kriterler esas alınmaktadır. Biyojen aminler (BA), tazelik ve/veya bozulma derecelerinin saptanması, yiyecek ve içeceklerin işlenme ve geliştirilmelerinin kontrolü amacıyla çeşitli gıdalarda kalite indeksleri olarak kullanılmaktadır (5). BA'lar organik, düşük moleküler ağırlıklı azotlu bileşikler olup $(6,7)$ enzimatik amino asit dekarboksilasyonu ile aldehit ve ketonların indirgeyici aminasyonuyla oluşmaktadırlar (8). Amino asitlerin mikrobiyal dekarboksilasyonu yoluyla BA oluşumu, bakteri türlerine, dekarboksilaz aktivitesi seviyesine ve amino asit substratının mevcudiyetine bağlıdır (9). BA'ların insanlarda bağışıklık sisteminin ve vasküler aktivitenin geliştirilmesi ve zihinsel fonksiyonların düzenlenmesi gibi çeşitli fizyolojik reaksiyonlarda etkileri bulunmaktadır. Bununla birlikte baş ağrısı, hipertansif krizler, ishal, alerji, kalp çarpıntısı ve kusma gibi farklı toksik etkilere neden olduğu da bilinmektedir $(8,10)$. Bu toksik etkiler; bireysel duyarlılık, BA tipi ve ekzojen BA'ları detoksifiye edebilen aminooksidaz enzimatik sistemleri ile etkileşime giren etanol veya monoaminooksidaz inhibitör maddelerinin tüketimi gibi çeşitli faktörlere bağlı olarak meydana gelmektedir (10).

BA'ların gıdalarda belli bir düzeydeki bulunuşu; aşırı mikrobiyal çoğalmanın, kötü hijyenik kalite ve gıda tazeliğinin dolaylı bir göstergesi olarak kabul edilmektedir $(5,10)$. Fermentasyon ve mikrobiyal olgunlaşma süreci bulunan gldalardaki BA üretim ve birikimini etkileyen faktörlere ilişkin bilgiler bilimsel olarak sunulmuştur (11). Fermente gıdalarda bulunan en yaygın BA'lar; histamin, tiramin, putresin, kadaverin, triptamin, feniletilamin, spermidin ve spermindir (8). Peynirler, üretim aşamalarında yer alan süreçler ve teknolojik işlemlerin etkisi gibi örneklendirilebilecek çok sayıda faktörün etkisiyle toksisiteden sorumlu başlıca gıdalar arasında yer almaktadır $(12,13)$. Biyojen aminlerin peynir türlerinde oluşumu ve birikimi için koşullar, serbest amino asitlerin mevcudiyeti, dekarboksilaz içeren bakterilerin varlığı ve bakteriyel büyümeye ve enzimatik aktiviteye izin veren çevresel faktörlerdir (14). Isıl işlem görmeyen sütten elde edilen peynirlerde başlangıç yüksek mikroorganizma sayısı BA oluşumunda önem arz etmektedir. Bununla birlikte üretim teknolojilerinde Isıl işlem düzenekleri yer alan peynirlerde de ısıl işlemlere dayanıklı non-starter laktik asit bakterileri BA üretiminden sorumludurlar (15).

Gıdalarda BA'lerin niceliksel tespiti amacıyla hızlı, ekonomik ve aynı zamanda doğruluk, hassasiyet ve algılama limitleri bakımından da güvenilir analitik metotların geliştirilmesi son zamanlarda önem kazanmıştır (16). BA'ların varlığının saptanması ve miktar tayinlerinin yapılması gıda analizlerinde karşılaşılan temel sorunları teşkil etmektedir. Bileşiklerin güçlü polar karakterleri, gıda matris örneklerinin karmaşık yapısı, düşük değişken konsantrasyon aralığı, potansiyel olarak karışan bileşiklerin varlığı, bileşiklerin spektrofotometrik, florometrik veya elektrokimyasal yöntemler gibi fizikokimyasal yöntemlerle saptanmasını sağlayabilecek intrinsik özelliklerinin olmaması ve birkaç biyojen aminin aynı anda oluşması gibi nedenler bu sorunlardan bazılarıdır. Geliştirilen analitik yöntemler genellikle amin ekstraksiyonuna ve türetmeye, ardından ayırma ve nicel olarak saptamaya dayanmaktadır. Ekstraksiyon ve gerektiği durumlarda türevlendirmeden sonra BA'ların belirlenmesi en yaygın olarak yüksek performanslı sıvı kromatografisi (HPLC), gaz kromatografisi (GC) ve kapiler elektroforez (CE) gibi kromatografik yöntemlerle gerçekleştirilir (17). Bununla birlikte, ince tabaka kromatografisi (TLC), iyon değişim kromatografisi (IEC) gibi metotlar da kullanılmaktadır (18).

Sunulan bu araştırmada Konya ilinde satışa sunulan Yeşil peynir örneklerinde biyojen aminlerin varlığının RP-HPLC yöntemiyle incelenmesi yanı sıra bazı fizikokimyasal ve mikrobiyolojik özelliklerinin de değerlendirilmesi amaçlandı.

\section{MATERYAL VE METOT}

\section{Numune Temini}

Araştırmada, Konya ilinde faaliyet gösteren gıda satış yerlerinde piyasaya sunulan toplam 50 adet Yeşil peyniri materyal olarak kullanıldı. Numuneler farklı üreticileri ve satış noktalarını temsil edecek şekilde toplandı. Örnekler aseptik koşullarda steril cam kavanozlara aktarılarak soğuk zincir şartlarında laboratuvara ulaştırıldı ve analizleri yapılıncaya kadar soğuk muhafazaya $\left(+4{ }^{\circ} \mathrm{C}\right)$ alındı.

\section{Biyojen Aminlerin Tayini \\ Reaktifler \\ Histamin (HIT), tiramin (TYA), putresin (PUT), kadaverin (CAD), triptamin (TRY), feniletilamin (PHA), spermidin (SPD) ve spermin (SPM), 1.7-diaminoheptan (iç standart, IS), amonyak, hidroklorik asit, sodyum karbonat, asetonitril ve dietil eter Merck (Darmstadt, Germany), Fluka (Buchs, Swit- zerland), Sigma-Aldrich (St. Louis, Missouri, USA), Supelco (Bellefonte, Pennsylvania, USA) ve LabScan'dan (Dublin, Ire- land) temin edildi. \\ Standart ve Örnek Solüsyonların Hazırlanması ve Türevlendirme}

Incelenen peynir numunelerindeki BA miktarı, standartların kalibrasyon eğrileri ile hesaplandı. 1-25 mg/l lineer aralıkta standart karışımları hazırlandı. Standartlar ve numuneler dansil klorür $(\mathrm{DCl})$ reaktifi ile türevlendirildi ve UV dedektörlü HPLC' de analiz edildi.

Peynir numunelerinden 10 'ar gr alınarak santrifüj tüpüne aktarıldı. Numunelerin üzerine 1000 pm'lik 1.7 diaminoheptan iç standartından (IS) $2 \mathrm{ml}$ ve $20 \mathrm{ml} 0.1 \mathrm{M} \mathrm{HCl}$ ilave edildi. Sonrasında oda sıcaklığında $10 \mathrm{dk}$ vortekslendi. Elde edilen peynir karışımı $12.000 \mathrm{~g}$ de $20 \mathrm{dk} 4{ }^{\circ} \mathrm{C}^{\prime}$ de santrifüj 
edildi. Süpernatant başka bir kaba aktarılarak tortuya aynı prosedür tekrar uygulandı. Elde edilen süpernatant karışım $50 \mathrm{ml}$ 'lik balon jojeye alınarak $0.1 \mathrm{M} \mathrm{HCl}$ ile 50 ml'ye tamamlandı.

Türevlendirme için seyreltilmiş ekstrakt ve standartlardan $1 \mathrm{ml}$ lik kısım viallere alınarak üzerine $0.5 \mathrm{ml}$ doymuş $\mathrm{NaHCO}_{3}$ çözeltisi eklendi. Üzerine asetonda çözülmüş dansyl chloride-DCl reaktifi $(5 \mathrm{mg} / \mathrm{ml}$ ) bulunan karışımdan $1 \mathrm{ml}$ ilave edildi. Reaksiyon karışımı, oda sıcaklığında $1 \mathrm{dk}$ kuvvetlice çalkalandı ve karanlık ortamda oda sıcaklığında $60 \mathrm{dk}$ bekletildi. Fazla miktarda ilave edilen DCl'yi nötralize etmek için karışıma $250 \mu \mathrm{l} \mathrm{NH} \mathrm{N}_{3}$ ilave edildi. Sonrasında karışım iki kez 1 $\mathrm{ml}$ miktarında dietil eterle ekstraksiyona tabi tutuldu. Üstte yer alan dietil eter fazları birleştirildi ve azot gazı altında uzaklaştırıldı. Kalıntı, asetonitril içerisinde yeniden çözülerek HPLC sistemine enjekte edildi $(19,20)$.

\section{RP-HPLC ile Biyojen Aminlerin Analizi}

Biyojen amin analizinde UV detektörlü 1200 serisi HPLC sistemi ve Chemstation B.03.02-2008 veri işlemcisi (Agilent Technologies Inc., Wilmington, Delaware, USA) kullanıldı. Asetonitril içinde çözülmüş $20 \mu \mathrm{l}$ numune, Zorbax Eclipse XDB C18 kolonuna (250x4.6 mm, $5 \mu \mathrm{m}$ film thickness, Agilent Technologies Inc., Wilmington, Delaware, USA) enjekte edildi. Moret ve ark. (21) tarafından geliştirilen su (A) ve asetonitril (B) gradient hareketli fazı ve $0.8 \mathrm{ml} / \mathrm{dk}$ akış hızlı analiz metodu kullanıldı. Bu metoda göre; başlangıçta \%35 A ve \%65 B olan karışım oranları, B çözücüsü \%80 (10dk), \%90 (12 dk) ve \%100 (16 dk) olana kadar kademeli olarak arttırıldı. \%100 olduğunda $25 \mathrm{dk}$ daha hareketli faz kolonla muamele edilerek analiz tamamlandı. UV dedektörün dalga boyu 254 $\mathrm{nm}$ olarak ayarlandı.

\section{Fizikokimyasal Analizler}

Numuneler, AOAC-2005 (22)'e göre toplam kuru madde, titre edilebilir asitlik (laktik asit cinsinden) ve tuz içerikleri açısından analizlere tabi tutuldu. $\mathrm{pH}$ değerleri potansiyometrik olarak dijital pH metre (InoLab pH 720 model, WTW, $\mathrm{GmbH}$, Weilheim, Germany) aracılığıyla ve su aktivitesi değerleri su aktivitesi cihazı (Novasina LabSwift-aw, 2600179 model, Lachen, Switzerland) ile belirlendi. Numuneler renk tayin cihazı (Minolta Company, CR-400, Osaka, Japan) kullanılarak L (beyazlık), a (yeşillik veya kırmızılık) ve b (sarılık veya mavilik) parametreleri bakımından analizlere tabi tutuldu. Beyaz seramik kalibrasyon plakası (Konica Minolta 13433102; $L=97.65, a=-0.10, b=-0.14$ ) ile kalibrasyon gerçekleştirildi. Ölçümler peynirin parçalı yapısından dolayı örneklerin yüzeyinden ve üst üste gelmeyen alanlarından olacak şekilde $20 \pm 2{ }^{\circ} C^{\prime}$ de 3 tekrar yapıldı ve ortalamaları hesaplandı.

\section{Mikrobiyolojik Analizler}

Mikrobiyolojik analiz amacıyla numuneler AOAC-2000 (23) direktiflerine göre hazırlandı. Numunelerden aseptik koşullarda 10 gr örnek alındı ve steril numune poşetlerine aktarıldı. Steril peptonlu fizyolojik tuzlu su çözeltisi (Merck 1.12535) ile homojenizatörde (Seward Laboratory,
Stomacher Lab-Blender 400-BA6021, London, England) 2 dk süreyle homojenize edildi. Homojenizasyon sonrası örnekler deney tüplerine aktarıldı ve seri dilüsyonlar oluşturuldu. Oluşturulan örnek seyreltmelerinden toplam aerobik mezofilik bakteri (TAMB) için Plate Count Agar-PCA (Merck 1.05463 ) besiyerinde $35^{\circ} \mathrm{C}^{\prime}$ de 48 saat inkübasyon gerçekleştirildi (24). Laktik asit bakterilerinden Lactobacillus türlerinin izolasyonunda DeMan Rogosa Sharp-MRS Agar (Merck 1.10660), Streptococcus ve Lactococcus türlerinin izolasyonunda ise M17 Agar (Merck, 1.15108) besiyerleri kullanıldı. Yayma plak yöntemi kullanılarak yapılan ekimler sonucunda MRS agarlar $37^{\circ} \mathrm{C}^{\prime}$ de 48 saat süre ile jarlar içerisinde Anaerocult C (Merck, 116275) kullanılarak anaerobik, M17 agarlar ise $37^{\circ} \mathrm{C}^{\prime}$ de 48 saat süre ile aerobik şartlarda inkübe edildi. İnkübasyon sonrasında sayım yapılarak sonuçlar koloni oluşturan birim-KOB/g olarak hesaplandı $(25,26)$.

\section{İstatiktiksel Analizler}

Tüm veri setlerine ilişkin tanımlayıcı istatistikler, aralık, ortalama, standart sapmalar Minitab 17 İstatistik Yazılımı (Computer software, Minitab Inc., State College, Pennsylvania, USA, 2010) ile hesaplandı.

\section{BULGULAR}

\section{Biyojen Amin Düzeyleri}

Yeşil peynirlerin toplam BA miktarlarına ilişkin elde edilen bulgular değerlendirildiğinde örneklerin en az, en çok ve ortalama içerikleri sırasıyla; $168.30,648.10$ ve $457.45 \pm 122.23$ $\mathrm{mg} / \mathrm{kg}$ olarak tespit edildi. Örneklerdeki baskın biyojen amin türleri olarak belirlenen tiramin ve histamin miktarlarının toplam BA ortalamalarının \%82'sini oluşturduğu gözlemlendi (Grafik 1).

Grafik 1. Örneklerde varlığı tespit edilen biyojen aminlerin \% miktarları

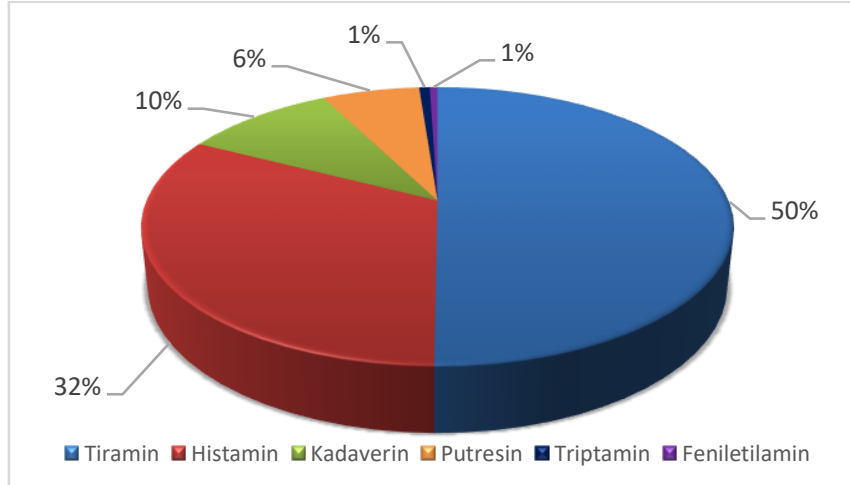

Incelenen tüm örneklerde tiramin ve histamin tespit edilirken tiramin miktarları 35.10-343.20 ve histamin miktarları da $27.60-224 \mathrm{mg} / \mathrm{kg}$ arasında değişiklik gösterdi. Kadaverin (44/50), putresin (39/50), triptamin (32/50) ve feniletila$\min (24 / 50)$ değerlerinin de sırasıyla; 0-86.20, 0-98.10, 08.70 ve $0-6.10 \mathrm{mg} / \mathrm{kg}$ arasında olduğu belirlendi. Örneklerde spermidin ve spermin varlığı saptanmadı. Varlığı saptanan BA türleri bakımından ortalama değerler; tiramin $229.41 \pm 95.63$ $\mathrm{mg} / \mathrm{kg}$, histamin $148.21 \pm 55.52 \mathrm{mg} / \mathrm{kg}$, kadaverin $45.34 \pm 29.52$ $\mathrm{mg} / \mathrm{kg}$, putresin $29.03 \pm 27.24 \mathrm{mg} / \mathrm{kg}$, triptamin $3.14 \pm 2.70$ 
$\mathrm{mg} / \mathrm{kg}$ ve feniletilamin $2.30 \pm 2.37 \mathrm{mg} / \mathrm{kg}$ olarak tespit edildi (Grafik 2).

Grafik 2. Peynir örneklerine ait biyojen amin ortalamaları $(\mathrm{mg} / \mathrm{kg})$

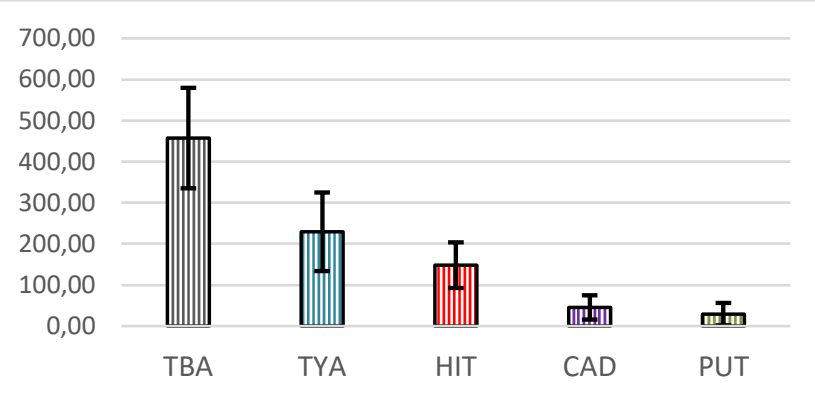

TBA: Toplam Biyojen Amin, TYA: Tiramin, HIT: Histamin, CAD: Kadaverin, PUT: Putresin

TBA: Toplam Biyojen Amin, TYA: Tiramin, HIT: Histamin, CAD: Kadaverin, PUT: Putresin

\section{Fizikokimyasal Analizler}

Peynir örneklerinde analiz edilen kuru madde, tuz, laktik asit cinsinden titre edilebilir asidite, $\mathrm{pH}$ ve $\mathrm{a}_{\mathrm{w}}$ değerleri yanı sıra renk parametrelerine ilişkin bulgular Tablo 1'de görülmektedir.

Tablo 1. Peynir örneklerinin fizikokimyasal analiz sonuçlari

\begin{tabular}{lrrr} 
Analiz Türü & En az & En çok & Ortalama \pm SD \\
\hline Kuru madde (\%) & 49.46 & 60.14 & $53.57 \pm 2.69$ \\
Tuz (\%) & 4.09 & 7.13 & $5.82 \pm 0.81$ \\
Asidite (\% L.A) & 0.68 & 1.36 & $1.13 \pm 0.18$ \\
pH & 5.43 & 6.87 & $6.21 \pm 0.37$ \\
$a_{w}$ & 0.933 & 0.974 & $0.948 \pm 0.01$ \\
Renk L & 66.43 & 83.11 & $76.70 \pm 3.90$ \\
Renk a & -4.54 & -2.59 & $-3.70 \pm 0.40$ \\
Renk b & 11.44 & 20.62 & $15.60 \pm 2.70$ \\
\hline
\end{tabular}

\section{Mikrobiyolojik Analizler}

Örneklerde TMAB sayıları 6.36-8.51 log KOB/g arasında tespit edildi. TMAB sayıları bakımından ortalama değerler ise $7.44 \pm 0.58 \log \mathrm{KOB} / \mathrm{g}$ olarak saptandı. Bununla birlikte MRS agar besiyerindeki Lactobacillus ve M17 agar besiyerindeki Streptococcus ve Lactococcus sayıları da sırasıyla; 6.15-6.94 log $\mathrm{KOB} / \mathrm{g}$ ve 6.24-7.56 log $\mathrm{KOB} / \mathrm{g}$ arasında bulundu. Lactobacillus ve Streptococcus ve Lactococcus sayıları için ortalama değerler; $6.47 \pm 0.26 \log \mathrm{KOB} / \mathrm{g}$ ve $7.09 \pm 0.40 \mathrm{log} \mathrm{KOB} / \mathrm{g}$ olarak tespit edildi (Grafik 3).

Grafik 3. Peynir örneklerine ait mikrobiyolojik analiz ortalamaları

$$
(\log \mathrm{KOB} / \mathrm{g})
$$

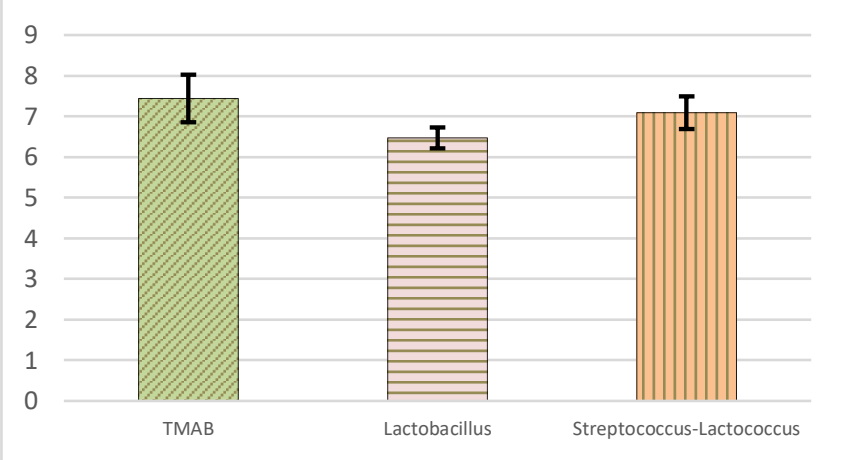

\section{TARTIŞMA VE SONUÇ}

Beslenmedeki yeri ve öneminin yanı sıra kültürel miras niteliği taşıyan bir gıda olan peynir, gerek tüketici talepleri gerekse teknolojik gelişmelere paralel olarak farklı şekillerde çeşitlendirilmiştir (27). Söz konusu çeşitliliğin diğer gıda türlerine kıyasla oldukça zengin olması genel anlamda peyniri analiz edilen herhangi bir parametre bakımından belli sınırlar içerisinde ifade edebilmeyi güçleştirmektedir. Benzer şekilde peynir türlerindeki toplam BA içeriği ve baskın amin türleri değişken çeşit ve miktarlarda olabilmektedir. Nitekim, geleneksel peynirlerin değerlendirildiği bilimsel çalışmalarda da BA tür ve miktarlarının değişiklik arz ettiği gözlemlenmektedir. Şenel ve ark. (28) Isıl işlem görmemiş sütlerden elde edilen Urfa ve Van otlu peynirlerinde ortalama toplam BA içeriklerini $28.00 \pm 5.8 \mathrm{mg} / \mathrm{kg}$ ve $18.60 \pm 2.5 \mathrm{mg} / \mathrm{kg}$ düzeyinde tespit etmişlerdir. Araştırmacılar Urfa peyniri örneklerinde baskın BA türünün tiramin olduğunu ve toplam ortalamanın $\% 65$ 'ini oluşturduğunu saptamışlardır. Bununla birlikte Van otlu peynirlerinde de sırasıyla tiramin, kadaverin ve histaminin baskın amin türleri olarak toplam BA miktarlarının $\% 71.50$ 'sini oluşturduğu ifade edilmiştir. Gürkan (29), olgunlaşmanın 90 . gününe ait $10^{\circ} \mathrm{C}^{\prime}$ de muhafaza edilen küflü Civil peynirlerinde toplam BA miktarının $228.94 \mathrm{mg} / \mathrm{kg}$ olduğunu belirtmiştir. Baskın BA türleri putresin ve kadaverin olarak tespit edilmiştir. Andıç ve ark (30), 30 adet otlu peynir örneğinin 10 tanesinde toplam BA miktarının $1.000 \mathrm{mg} / \mathrm{kg}$ seviyesinden yüksek ve tüm örnekler için 99.50-4723.00 mg/kg arasında olduğunu saptamışlardır. Araştırmacılar, BA türlerine göre ortalama düzeylerin ise; tiraminde $360.3 \pm 46.3$, kadaverinde 288.4 \pm 79.4 , histaminde $197.9 \pm 28.3$, putresinde $192.5 \pm 38.2$, triptaminde $103.2 \pm 6.7$ ve feniletilaminde $33.6 \pm 5.8 \mathrm{mg} / \mathrm{kg}$ olduğunu belirtmişlerdir. Diler ve ark (31), Isıl işlem uygulayarak deneysel olarak ürettikleri Ezine peyniri numunelerinde depolamanın 12. ayındaki BA miktarlarını putresinde $136.95 \pm 11.56$, feniletilaminde $65.37 \pm 5.96$, tiraminde $50.21 \pm 4.77$, histaminde $49.67 \pm 4.16$ ve triptaminde $33.78 \pm 4.43 \mathrm{mg} / \mathrm{kg}$ olarak bulmuşlardır. Erdem ve Patır (32), Elazığ ilinde satışa sunulan 40 adet kuru tulum peynirinin histamin düzeylerinin $70.65 \pm 67.38 \mathrm{mg} / \mathrm{kg}$ olduğunu ifade etmişlerdir. Akgül ve ark (33), 20'şer adet tulum ve kaşar peyniri örneğinde toplam BA (19.30 ve $16.20 \mathrm{mg} / \mathrm{kg}$ ), tiramin ( 5.6 ve $6.8 \mathrm{mg} / \mathrm{kg}$ ), putresin (5.1 ve $0.9 \mathrm{mg} / \mathrm{kg}$ ), kadaverin (4.5 ve $1.8 \mathrm{mg} / \mathrm{kg}$ ), feniletilamin (1.6 ve $2.2 \mathrm{mg} / \mathrm{kg}$ ), triptamin (1.3 ve $0.7 \mathrm{mg} / \mathrm{kg}$ ) ve histamini (1.2 ve $3.9 \mathrm{mg} / \mathrm{kg}$ ) farklı peynir türlerinde değişen oranlarda tespit ettiklerini ileri sürmüşlerdir. Biyojen amin içeriklerindeki farklılıkların değerlendirilmesinde peynir türü yanı sıra çok sayıda faktörden bahsedilebilmektedir. Ürün üretim teknolojisinde yer alan uygulamalar, mikrobiyolojik flora bileşimi, mevcut mikroorganizmaların proteolitik ve dekarboksilaz aktiviteleri, olgunlaşma sürecinde gerçekleşen biyokimyasal reaksiyonlar ve depolama koşulları bu faktörler arasında yer almaktadır (6, 34). Bu bakımdan peynir türlerine göre olgunlaştırma süresinin $(31,35,36)$, hammaddeye uygulanan ısıl işlemlerin (15, 36), diğer üretim uygulamaları ile muhafaza koşulları ve hijyenik tedbirlerin $(13,17,37)$ önem arz ettiği ileri sürülmektedir. Peynirlerin olgunlaşma reaksiyonları göz önüne alındığında kazein proteolizinin en önemli safhalardan biri 
olduğunu söylemek mümkündür. Proteoliz esnasında proteaz ve peptidaz aktivitesi kazeinin yıkımına neden olmakta ve bununla birlikte BA prekürsörleri olan serbest aminoasitler oluşmaktadır. Olgunlaştırma süresinin artması, uygun olmayan muhafaza koşulları gibi faktörler bu bakımdan BA oluşumu miktarlarındaki artışı da beraberinde getirmektedir $(15,29,38)$.

Peynir örneklerinin kuru madde, tuz, titre edilebilir asidite, $\mathrm{pH}$ ve $\mathrm{a}_{\mathrm{w}}$ değerleri ortalamaları sırasıyla; \%53.57 \pm 2.69 ; $\% 5.82 \pm 0.81 ; \% 1.13 \pm 0.18$ LA; $6.21 \pm 0.37$ ve $0.948 \pm 0.01$ olarak tespit edildi. Kuru tipte tulum peyniri olarak sınıflandırılabilen Yeşil peynir örneklerine ait kuru madde değerleri yarı sert peynirlere ait değerlerle benzerlik göstermektedir. Elde edilen bulguların Yeşil peynirin kuru madde içeriklerinin saptandığı diğer bazı araştırma bulgularından yüksek olduğu gözlemlenmiştir. Hayaloğlu ve ark (2), Güner ve Telli (1), Özgören ve Seçkin (39) Yeşil peynir numunelerinin kuru madde ortalamalarını sırasıyla $\% 50.03, \% 51.41$ ve $\% 49.30$ olarak tespit etmişlerdir. Hafif tuzlu bir lezzete sahip olduğu bilinen Yeşil peynirlere ait tuz değerleri Hayaloğlu ve ark (2) verilerinden yüksek, Güner ve Telli (1) verilerine benzer ve Özgören ve Seçkin (39) bulgularından düşük bulunmuştur. Gıdalarda BA oluşumunda tuz konsantrasyonunun oldukça önemli olduğu bilinmektedir. Tuzun histidin dekarboksilaz aktivitesi üzerindeki inhibe edici etkisinin gözlemlendiği \%5'lik konsantrasyonları histamin oluşumunda temel sınırlayıcı faktörler arasındadır (40). Bununla birlikte peynirlerde tuz içeriklerinin; kazein ağının hidrasyonu, kalsiyum ve para-kazeinat kompleksinin etkileşimleri, su ve enzim aktivitesiyle mikrobiyal dinamikler üzerinde etkili olduğu ve çok sayıda amin oluşumunu da yavaşlattığı ileri sürülmektedir $(41,42)$. Laktik asit cinsinden titre edilebilir asidite değerleri benzer amaçla yürütülen çalışma bulgularından yüksek bulunmuştur. Nitekim, Güner ve Telli (1), Özgören ve Seçkin (39) ve Hayaloğlu ve ark (2) asidite değerlerini sırasıyla; $0.61,0.84$ ve 0.96 olarak tespit ettiklerini bildirmişlerdir. Yeşil peynirlere ait $\mathrm{pH}$ değerleri ise Hayaloğlu ve ark (2) verilerine benzer, Güner ve Telli (1) verilerinden düşük ve Özgören ve Seçkin (39) bulgularından yüksek bulunmuştur. Peynirlerin $\mathrm{pH}$ ve asidite değerleri, dekarboksilaz aktivitesini etkileyen dolayısıyla da BA oluşumunda oldukça önem arz eden faktörler arasındadır. pH'nın mikrobiyal aktivite üzerindeki etkisi BA oluşumunda sınırlayıcı etkenlerdendir. Bununla birlikte aminoasit dekarboksilaz etkinliğinin asitliğin artışıyla birlikte paralel olarak artış gösterdiği ve $\mathrm{pH} 4,0$ ile 5,5 arasında da en etkin seviyede olduğu ifade edilmektedir (43). Ülkemizde geleneksel olarak üretilen bazı peynir çeşitlerinin fizikokimyasal özelliklerine ilişkin bilimsel veriler sunulmuştur. Örneğin; Hayaloğlu ve Kırbağ (44), farklı satış yerlerinden temin ettikleri 30 adet küflü peynir örneğinin nem içeriklerinin \%37.65 ile 53.65 arasında olduğunu bildirmişlerdir. Araştırmacılar örneklerin pH değerlerinin 5.52 ile 7.22 arasında değiştiğini ve ortalama $6.29 \pm 0.28$ olduğunu saptamışlardır. Özgören ve Seçkin (39), farklı bölgelerde üretimi yapılan küflü peynirlere ait fizikokimyasal özellikleri tespit etmeyi amaçlamışladır. Araştırmacılar, Isparta, Kayseri, Mersin ve Erzurum illerinde üretilen küflü peynirlerin kuru madde içeriklerini sırasıyla; $\% 52.64, \% 60.55$, $\% 59.79$ ve $\% 44.12$ olarak bulmuşlardır. Tuz içerikleri \%4.23,
$\% 4.33, \% 4.30$ ve \%5.48; laktik asit cinsinden titre edilebilir asidite miktarları \%0.82, \%0.71, \%1.08 ve \%1.11; $\mathrm{pH}$ değerleri de 5.49, 4.92, 5.70 ve 4.65 olarak saptanmıştır. Akkoç ve ark (45), otlu peynirlerde $\mathrm{pH}$ değerlerinin 4.2 ile 5.8 arasında değişkenlik gösterdiğini ifade etmişlerdir. Araştırmacılar, $\mathrm{pH}$ değerleri ile histamin miktarları arasında bir korelasyon bulunmadığını ileri sürmüşlerdir. Diler ve ark (31), Ezine peynirlerinde 12 aylık depolama süresi sonunda $\mathrm{pH}$ ve kuru maddede tuz miktarlarını $4.54 \pm 0.01$ ve $\% 12.25 \pm 0.07$ olarak tespit etmişlerdir. Erdem ve Patır (32), tulum peynirlerinde orta-

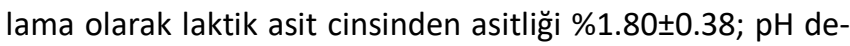
ğerlerini 5.10 \pm 0.40 ; $a_{w}$ değerlerini $0.930 \pm 0.030$; kuru madde oranlarını $\% 54.94 \pm 5.13$ ve tuz içeriklerini ise $\% 3.29 \pm 0.60$ olarak bildirmişlerdir. Öztürkoğlu-Budak ve ark (46), Divle peynirlerinde olgunlaşmanın 120 . gününde kuru madde değerlerinin $52.88 \pm 0.87$ ile $56.25 \pm 0.69, \mathrm{pH}$ düzeylerinin $5.06 \pm 0.03$ ile $5.14 \pm 0.02$, tuz miktarlarının da $3.45 \pm 0.23$ ile $3.80 \pm 0.23$ arasında tespit edildiğini bildirmişlerdir. Dervişoğlu ve ark (47), Keş peynirlerinde kuru madde ve $\mathrm{pH}$ ortalamalarını $56.17 \pm 6.07$ ve $4.75 \pm 0.59$ olarak bulmuşlardır. Peynir örnekleri renk parametreleri bakımından ele alındığında $L$, $a$ ve $b$ değerleri ortalamaları sırasıyla; $76.70 \pm 3.90,-3.70 \pm 0.40$ ve $15.60 \pm 2.70$ olarak tespit edildi. Çeşitli geleneksel ve işlenmiş peynir türleri için teknolojik işlemlerin ve olgunlaşma sürecindeki fizikokimyasal reaksiyonların etkilerini izlemek amacıyla kalitatif ve kantitatif renk değerlendirmeleri yapılmaktadır (48). Tat ve tekstür oluşumuna kıyasla fizikokimyasal reaksiyonlar ve renk karakteristiklerindeki değişimler izlenmesi ve yorumlanması daha karmaşık süreçlerdir (49). Peynir çeşitlerine ilişkin tüm fizikokimyasal değerler arasındaki farklılıkların hammadde özellikleri, üretim teknolojileri, olgunlaşma süresi ve özellikle muhafaza ve satış koşullarından kaynaklandığı düşünülmektedir.

BA'ların peynirlerde oluşumu esas olarak, Lactobacilli, Enterococci, Micrococci ve birçok Enterobacteriaceae suşu gibi amino asit dekarboksilaz aktivitesine sahip mikroorganizmaların varlığı ve mikrobiyal kontaminasyon kaynaklıdır (34). Isıl işlem görmeyen sütten elde edilen peynirlerde başlangıç yüksek mikroorganizma sayısı ve pastörize sütlerden üretilen peynirlerde ise özellikle ısıl işlemlere dayanıklı nonstarter laktik asit bakterileri BA üretiminden sorumludurlar (15). Dolayısıyla peynirlerin mevcut mikroorganizma türlerine ilişkin sayısal değerlendirmeler BA miktarlarıyla ilişkilendirilebilmektedir. Sunulan çalışmada destekler nitelikte TMAB sayılarının nispeten fazla saptandığı örneklere ilişkin toplam BA değerlerinin de paralel olarak yüksek bulunduğu gözlemlenmiştir. Geleneksel peynirlerin mikrobiyolojik özelliklerinin ortaya konmasını amaçlayan bilimsel çalışmalar bulunmaktadır. Örneğin; Şengün ve ark (50), Isparta ilinde üretilen geleneksel küflü çömlek peynirinin mikroflorasını incelemişlerdir. Araştırmacılar, laktik asit bakterisi sayılarını 7.19 ile $8.61 \log \mathrm{KOB} / \mathrm{g}$ arasında tespit etmişlerdir. Erzurum ilinde satışa sunulan Civil peyniri örneklerinde yürütülen çalışmada laktik asit bakterisi ve TMAB düzeyleri ortalamaları sırasıyla 6,41 ve $7.44 \log \mathrm{KOB} / \mathrm{g}$ olarak bildirilmiştir (51). Şengül (52), Civil peynirlerinin TMAB düzeylerinin $1.0 \times 10^{7}$ ile $7.3 \times 10^{8}$; laktik asit bakterisi sayılarının da $1.1 \times 10^{4}$ ile $8.0 \times 10^{7} \mathrm{KOB} / \mathrm{g}$ arasında değiştiğini ifade etmiştir. Atasoy ve ark (53), Şanlıurfa'da 
satışa sunulan peynir örneklerinde TMAB düzeylerinin $2.33 \times 10^{6}$ ile $2.22 \times 10^{7} \mathrm{KOB} / \mathrm{g}$ arasında değiştiğini bildirmişlerdir. Çetinkaya ve Soyutemiz (54), geleneksel tekniklerle üretilen kaşar peynirlerinde TMAB sayılarını 5.36-6.44 log $\mathrm{KOB} / \mathrm{g}^{-1}$ ve MRS ve $\mathrm{M} 17$ agarda laktik asit bakteri sayılarını da sırasıyla 7.08-7.40 ve $5.25-5.76 \log \mathrm{KOB} / \mathrm{g}^{-1}$ olarak tespit etmişlerdir. Hayaloğlu ve Kırbağ (44), küflü peynirlerde TMAB değerlerinin 8.26-10.69 log $\mathrm{KOB} / \mathrm{g}$ arasında ve ortalama $9.31 \pm 0.53 \log \mathrm{KOB} / \mathrm{g}$ düzeyinde olduğunu saptamışlardır. Temelli ve ark (55), beyaz peynirlerde TMAB değerlerini soğuk muhafazada $6.14 \pm 0.84$, vakum paketli ürünlerde de $6.17 \pm 0.73 \log \mathrm{KOB} / g$ olarak bulmuşlardır.

Sonuç olarak, gıda kaynaklı hastalıkların küreselleşen dünyada nüfusun büyük çoğunluğunu etkiliyor olması, üretim ve satış aşamalarında olası tehlikelere maruziyetin engellenmesi ve/veya minimuma indirilmesi için alınacak tedbirlerin önemini artırmaktadır (5). Sunulan çalışmada tespit edilen toplam BA miktarları ve baskın aminler olarak saptanan tiramin ve histamin düzeyleri, Yeşil peynirin hammadde temininden tüketime sunulana kadarki tüm aşamalarında bir üretim standardizasyonu sağlanmasının ve asgari hijyenik koşulların oluşturulmasının gerekliliğini ortaya koymaktadır. Bununla birlikte tiraminin farklı gıdalarda kalite indikatörü olarak yeni teknikler aracılığıyla hızlı tespitinin amaçlandığı güncel çalışmalar ve peynir kaynaklı histamin toksikasyonu vakalarında bildirilen limit değerler (56) göz önüne alındığında da elde edilen bulgular tüketici sağlığını yakından ilgilendirmektedir. Yeşil peynir üretim hattında yer alan tüm uygulamaların ve koşulların BA oluşumuna neden olabilecek olası etkileri bakımından ele alınmalarının gıda güvenliğinin temininde etkin olacağı açıktır. Bu amaçla, üretim ve satış aşamalarında kontrol edilebilir parametrelerin modifikasyonu ile mikrobiyolojik kriterlerin birlikte değerlendirilmesinin önem arz ettiği düşünülmektedir.

\section{KAYNAKLAR}

1. Güner A, Telli N. (2011). A Survey on the Presence of Listeria monocytogenes in Various Semi-Hard Cheeses from Different Regions of Turkey. J Anim Vet Adv. 10 (14): 1890-1894.

2. Hayaloğlu AA, Brechany EY, Deegan KC, McSweeney PLH. (2008). Characterization of the Chemistry, Biochemistry and Volatile Profile of Kuflu Cheese, a Mould-Ripened Variety. LWT Food Sci and Technol. 41 (7): 1323-1334.

3. Kamber U, Terzi G. (2007). The Traditional Cheeses of Turkey: Central Anatolian Region. Food Rev Int. 24 (1): 74-94.

4. Guley Z, Uysal HR, Kilic S. (2014). Lactic Acid Bacteria Flora of Konya Kuflu Cheese: A Traditional Cheese from Konya Province in Turkey. J Microbiol Biotechnol Food Sci. 2021: 238-242.

5. Ruiz-Capillas C, Herrero AM. (2019). Impact of Biogenic Amines on Food Quality and Safety. Foods. 8 (2): 62, 2-16.

6. Linares DM, del Río B, Ladero V, et al. 2012). Factors Influencing Biogenic Amines Accumulation in Dairy Products. Front Microbiol. 3: 180.

7. Doeun D, Davaatseren M, Chung MS. (2017). Biogenic Amines in Foods. Food Sci Biotechnol. 26 (6): 1463-1474.

8. Li B, Lu S. (2020). The Importance of Amine-Degrading Enzymes on The Biogenic Amine Degradation in Fermented Foods: A Review. Process Biochem. 99: 331-339.
9. Naila A, Flint S, Fletcher G, Bremer P, Meerdink G. (2010). Control of Biogenic Amines in Food-Existing and Emerging Approaches. J Food Sci. 75 (7): 139-150.

10. Tabanelli G. (2020). Biogenic Amines and Food Quality: Emerging Challenges and Public Health Concerns. Foods. 9 (859): 14.

11. Comas-Basté $O$, Luz Latorre-Moratalla M, Sánchez-Pérez $S$, Teresa Veciana-Nogués $M$, del Carmen Vidal-Carou M. (2019). Histamine and Other Biogenic Amines in Food. From Scombroid Poisoning to Histamine Intolerance. In: Biogenic Amines. Proestos C (ed). IntechOpen, London, United Kingdom: 1-19.

12. Benkerroum N. (2016). Biogenic Amines in Dairy Products: Origin, Incidence, and Control Means. Compr Rev Food Sci F. 15 (4): 801-826.

13. Costa MP, Rodrigues BL, Frasao BS, Conte-Junior CA. (2018). Biogenic Amines as Food Quality Index and Chemical Risk for Human Consumption. In: Food Quality: Balancing Health and Disease. Elsevier, Handbook of Food Bioengineering. Holban AM, Grumezescu AM (eds.). Academic Press, London, United Kingdom: 75-108.

14. Chaidoutis E, Migdanis A, Keramydas D, Papalexis P. (2019). Biogenic Amines in Food as a Public Health Concern an Outline of Histamine Food Poisoning. Arch Hell Med. 36 (3): 419-425.

15. Poveda JM, Molina GM, Gómez-Alonso S. (2016). Variability of Biogenic Amine and Free Amino Acid Concentrations in Regionally Produced Goat Milk Cheeses. Journal Food Compos Anal. 51: 85-92.

16. Sentellas S, Nuñez O, Saurina J. (2016). Recent Advances in the Determination of Biogenic Amines in Food Samples by (U)HPLC. J Agric Food Chem. 64: 7667-7678.

17. Papageorgiou M, Lambropoulou D, Morrison C, et al. (2018). Literature Update of Analytical Methods for Biogenic Amines Determination in Food and Beverages. TrAC Trend Anal Chem. 98: 128-142.

18. Dadáková E, Křížek M, Pelikánová T. (2009). Determination of Biogenic Amines in Foods Using Ultra-Performance Liquid Chromatography (UPLC). Food Chem. 116 (1): 365-370.

19. Komprda T, Novická K, Kalhotka L, Smělá D. (2005). Biogenic Amine Content in Sterilised and Pasteurised Long-Term Stored Processed Cheese. Czech J Food Sci. 23: 209-216.

20. Innocente N, Biasutti M, Padovese M, Moret S. (2007). Determination of Biogenic Amines in Cheese Using HPLC Technique and Direct Derivatization of Acid Extract. Food Chem. 101 (3): 1285-1289.

21. Moret S, Smela D, Populin T, Conte LS. (2005). A Survey on Free Biogenic Amine Content of Fresh and Preserved Vegetables. Food Chem. 89: 355-361.

22. AOAC. (2005). Official Methods of Analysis. Association of Official Analytical Chemists. 18th ed. Association of Official Analytical Chemists Inc, Gaithersburg, Maryland, USA.

23. AOAC. (2000). Official Methods of Analysis. Association of Official Agricultural Chemists. 17th ed. The Association of Agricultural Chemists Inc, Washington, USA.

24. FDA-BAM. (2001). Aerobic plate count Agar. Food and Drug Administration, Bacteriological Analytical Manual Online. U.S. Food \& Drug Administration Center for Food Safety \& Applied Nutrition.

25. Kosikowski FV, Mistry VV. (1997). Cheese and Fermented Milk Foods. Procedures and Analysis, Vol. 2, Westport, CT, USA, 208264. 
26. Papageorgiou DK, Abrahim A, Bori M, Doundounakis S. (1998). Chemical and Bacteriological Characteristics of Pichtogalo Chanion Cheese and Mesophilic Starter Cultures for its Production. J Food Protect. 61: 688-692.

27. Telli N, Günhan RS, Telli AE. (2018). Konya Ovası Projesi (KOP) Bölgesi Geleneksel Peynirleri ve Coğrafi İşaretleme. 6. Uluslararası KOP Bölgesel Kalkınma Sempozyumu. 26-28 Ekim, 10831084, Konya-Türkiye.

28. Şenel E, Yıldız F, Yetişemeyen A, et al. (2012). Evaluation of The Biogenic Amine Content and Some Chemical and Microbiological Properties of Urfa and Van Herby Cheeses. Kafkas Univ Vet Fak Derg. 18 (4): 537-544.

29. Gürkan H. (2013). Küflü Civil Peynirlerde Aroma Gelişimi ve Biyojen Amin Varlığının Belirlenmesi. Yüksek Lisans Tezi. İnönü Üniversitesi Fen Bilimleri Enstitüsü, Malatya.

30. Andic S, Genccelep H, Kose S. (2010). Determination of Biogenic Amines in Herby Cheese. Int J Food Prop. 13 (6): 1300-1314.

31. Diler $M$, Akbağ $E$, Işık V, et al. (2018). Isıl İşlem ve Olgunlaştırma Sürelerinin Ezine Peynirinde Biyojen Amin Oluşumuna Etkileri. Gıda. 43 (4): 687-701.

32. Erdem G, Patır B. (2017). Elazığ'da Tüketime Sunulan Tulum Peynirlerinde Histamin Düzeyleri ile Bazı Kimyasal Kalite Parametreleri Üzerine Araştırmalar. FÜ Sağ Bil Vet Derg. 31 (3): 235-241.

33. Akgül FY, Yetişemiyen A, Şenel E, et al. (2019). Effects of Microorganism Count and Physicochemical Properties of Tulum and Kashar Cheeses to Biogenic Amine Formation. Turk J Food Agric Sci. 7 (4): 560-566.

34. Martuscelli M, Gardini F, Torriani S, et al. (2005). Production of Biogenic Amines During the Ripening of Pecorino Abruzzese Cheese. Int Dairy J. 15 (6-9): 571-578.

35. Andiç S, Tunçtürk Y, Gençcelep IJ. (2015). Farklı Otların Otlu Peynirin Biyojen Amin İçeriği ve Bazı Özellikleri Üzerine Etkisi. Gıda. 40 (1): 1-8.

36. Bogdanović T, Petričević S, Brkljača M, Listeš I, Pleadin J. (2020). Biogenic Amines in Selected Foods of Animal Origin Obtained from The Croatian Retail Market. Food Addit Contam Part A. 37 (5): 815-830.

37. Renes E, Diezhandino I, Fernandez D, et al. (2014). Effect of Autochthonous Starter Cultures on The Biogenic Amine Content of Ewe's Milk Cheese Throughout Ripening. Food Microbiol. 44: 271-277.

38. Flasarová R, Pachlová V, Buňková L, et al. (2016). Biogenic Amine Production by Lactococcus Lactis subsp. Cremoris Strains in the Model System of Dutch-Type Cheese. Food Chem. 194: 68-75.

39. Özgören E, Seçkin AK. (2012). Türkiye'de Ticari Ölçekte Üretilen Bazı Küflü Peynirlerin Kalite Özelliklerinin Belirlenmesi. Akademik Gıda. 10 (2): 55-62.

40. Shabby AR. (1996). Significance of Biogenic Amines to Food Safety and Human Health. Food Res Int. 29: 675-690.

41. Schirone M, Tofalo R, Mazzone G, Corsetti A, Suzzi G. (2011). Biogenic Amine Content and Microbiological Profile of Pecorino Di Farindola Cheese. Food Microbiol. 28: 128-136.
42. Rulikowska A, Kilcawley KN, Doolan IA, et al. (2013). The Impact of Reduced Sodium Chloride Content on Cheddar Cheese Quality. Int Dairy J. 28: 45-55.

43. Santos MHS. (1996). Biogenic Amines: Their Importance in Foods. Food Microbiol. 29: 213-231.

44. Hayaloglu AA, Kirbag S. (2007). Microbial Quality and Presence of Moulds in Kuflu Cheese. Int J Food Microbiol. 115: 376-380.

45. Akkoç Z, İncili GK, İlhak Oi. (2018). Otlu Peynirlerde Histamin, Bazı Mikrobiyolojik ve Kimyasal Özelliklerin Araştırılması. FÜ Sağ Bil Vet Derg. 32 (2): 87-92.

46. Ozturkoglu-Budak S, Gursoy A, Aykas DP, et al. (2016). Volatile Compound Profiling of Turkish Divle Cave Cheese During Production and Ripening. J Dairy Sci. 99 (7): 5120-5131.

47. Dervisoglu M, Tarakci Z, Aydemir O, Temiz H, Yazici F. (2009). A Survey on Selected Chemical, Biochemical and Sensory Properties of Kes Cheese, a Traditional Turkish Cheese. Int J Food Prop. 12 (2): 358-367.

48. Rohm H, Jaros D. (1996). Colour of Hard Cheese. Z Lebensm Unters Forsch. 203: 241-244.

49. El-Nimr AA, Eissa HA, El-Abd MM, et al. (2010). Water Activity, Color Characteristics and Sensory Properties of Egyptian Gouda Cheese During Ripening. J Am Sci. 6 (10): 447-453.

50. Şengün IY, Karapınar M, Yaman DB, Yenice E. (2006). Isparta Illi ve Yöresine Ait Geleneksel Küflü Çömlek Peynirinin Mikroflorası Üzerine Bir Araştırma. Türkiye 9. Gıda Kongresi; 24-26 Mayıs 2006, Bolu.

51. Yildiz F, Yetisemiyen A, Senel E, et al. (2010). Some Properties of Civil Cheese: A Type of Traditional Turkish Cheese. Int J Dairy Technol. 63 (4): 575-580.

52. Şengül M. (2006). Microbiological Characterization of Civil Cheese, a Traditional Turkish Cheese: Microbiological Quality, Isolation and Identification of its Indigenous Lactobacilli. World J Microbiol Biotechnol. 22 (6): 613-618

53. Atasoy FA, Türkoğlu H, Özer BH. (2003). Şanlıurfa İlinde Üretilen ve Satışa Sunulan Süt, Yoğurt ve Urfa Peynirlerinin Bazı Mikrobiyolojik Özellikleri. HRÜ Ziraat Fak Derg. 7: 77-83.

54. Çetinkaya F, Soyutemiz GE. (2006). Microbiological and Chemical Changes Throughout the Manufacture and Ripening of Kashar: A Traditional Turkish Cheese. Turk J Vet Anim Sci. 30: $397-$ 404.

55. Temelli S, Anar S, Sen C, Akyuva P. (2006). Determination of Microbiological Contamination Sources During Turkish White Cheese Production. Food Control. 17: 856-861.

56. European Food Safety Authority-EFSA. (2011). Scientific Opinion on Risk Based Control of Biogenic Amine Formation in Fermented Foods. EFSA J. 9, 2393.

\section{Sorumlu Yazar:}

Nihat TELLi

Konya Teknik Üniversitesi, Teknik Bilimler Meslek

Yüksekokulu, Gıda Teknolojisi Programı, Konya, TÜRKiYE

E-posta:ntelli@ktun.edu.tr 